Ciência e Natura, Santa Maria, v. 37 n. 3 esp. 2015, p. 70-74

Revista do Centro de Ciências Naturais e Exatas - UFSM

ISSN impressa: 0100-8307 ISSN on-line: 2179-460X

\title{
ciênciaenatura
}

\section{Evaluation of information technology management roles in sales Food Industries Case Study Food companies Khorasan Razavi}

\author{
Mostafa Mashhadi ${ }^{1}$, Mostafa Mazaheri Tehrani ${ }^{2,},{ }^{*}$, Mojtaba Porsalimi ${ }^{3}$ \\ ${ }^{1}$ Young Researchers and Elite Club, Quchan Branch, Islamic Azad University, Quchan, Iran \\ ${ }^{2}$ Professor, Department of Food Science, Faculty of Agriculture, Ferdowsi University of Mashhad \\ ${ }^{3}$ Associate Professor, Department of Management, Faculty of Management and Economics, \\ Ferdowsi University of Mashhad
}

\begin{abstract}
While many quality products should be only a short time in the market such as, and must give way to the final product tastes, preferences and needs of customers are compatible. Neglect or failure to timely delivery to our customers' requests may be too expensive. These conditions have caused the issue is important information for manufacturing organizations. The purpose of this study was to investigate new methods of information technology, sales of food industry in Iran, with manufacturing units of Khorasan, as a major hub for food production in the country. A questionnaire was developed for this study. Application information technology management by studying four parameters affecting the sale: Official Website, Internet sales of electronic business, Internet advertising and social networking As well as customer relationship management, field tested and evaluated. The results of field research 50 companies in various industries, including: Milk and dairy products, Beverages, Canning and juice, Meat and meat products, Cereal and flour products, Fermentation industry, Additives and spices the target population has been concluded. The results show that if Management of information technology (IT) as a principle and right of sale system used food factories Makes it easy to customer order, reduce the costs of marketing and advertising, and increasing the efficiency of product produced.
\end{abstract}

Keywords: Information Technology, Internet sales, e-commerce, online advertising, customer relationship management. 


\section{Introduction}

$\mathrm{T}$ he purpose of this study was to investigate new methods of information technology, sales of food industry in Iran, Khorasan Razavi province of unit production, food production as a major hub of the country. In this study, a questionnaire was prepared, and IT application sales unit to investigate the role of IT products sales four variables influence such official website, online sales of electronic business, Internet advertising and social networking and relationship management with CRM customer as a field has been assessed, the results of field research has been concluded.

\section{2- Materials and methods}

Of the 50 field research was carried out to analyze the companies in six industries such as milk and dairy products, flour products, flour, meat and meat products, beverages (including mineral water, soft drinks, water and beverages, tea and coffee ), canned juices, jams and sauces and other industries (including additives and spices, packaging and sugar) were classified and analyzed, and the results are shown on the chart by Excel In the presence or absence of each of the variables studied in the unit manufacturing industry, and if the answer is positive, its role and influence in the sale of products and the role of information technology in the changing, the question is. Replying to questions Sales Manager is responsible for the production unit. Food plants Khorasan Razavi as the statistical population studied and field research were the industries and factories is as follows:

Milk and dairy products: Khorasan Pegah, Multi, Dairy Razavi, Sabah, Kanyar, Golshad, Paloma,Ashena,Nooshin Toos,Dorna,Behshiran Nemone Shargh,Afarin Jam. Flour and flour products:Nane Razavi,Shahre Babana,Max, Khadivpor, Donuts Pedar,Shariyar kam,Shaker Toos,Arde Razavi, Parsan Arde Toos, Arde Gandom Kob. Meat products: Meat Industrial Complex Mashhad, Marlik,Yademan Gosht Khorasan . Drinks (such as mineral water, soft drinks, water and beverages, tea and coffee): Coffee multi, Zamzam Mashhad, Nader Agroindustrial, Glchkan, Nick Noosh Toos. Canned food, juice, jam and sauce: Zoshk,
Arshiya, Shahd Gole, Shahsavand Simin, Be Saba , Razavi products, Shana, Mahvand, Deland. Other industries (including additives and spices, packaging, and sugar): Razavi leaven, Saina, Zarchekan, salt-star East, Shahsavand gold, Jahan saffron, dates Hanan, Chitoz, Mokaram sugar.

The first question: Is your manufacturing unit to inform the official website to introduce and sell their products? Yes No .....

The impact website manufacturing unit in organizational performance is to what extent?

Only information ............ Products and Information .......... Product information and sales

The second question: Do you have internet sales and e-commerce manufacturing unit uses?

Yes complete ........Yes, incomplete ........No

Which model do you use e-commerce? B2B B2C B2G Other.....

The impact and the role of e-commerce sales is to what extent?

The third question:Is your manufacturing unit of Internet sites and social networks to advertise their goods and the introduction of using the? Yes.......... No ........

If you use, say, the role and impact on sales?

The fourth question:Do you have a customer relationship management CRM manufacturing unit used? Yes No

If you use role and performance in sales and corporate objectives is what?

\section{Results and discussion}

\subsection{The results of the first question}

Having a website is shown in Figure 1: Milk and dairy products: All companies in this industry have a website. Beverages: All companies in this industry have a website .Canning: $80 \%$ of companies in this industry have a website. Flour and flour products: $60 \%$ of companies in this industry have a website. Meat and meat products: $65 \%$ of companies in this industry have a website. Other industries: $80 \%$ of companies in this industry have a website .Almost $90 \%$ of companies have Web sites contain information involving the introduction of product and only $10 \%$ are informational only. 


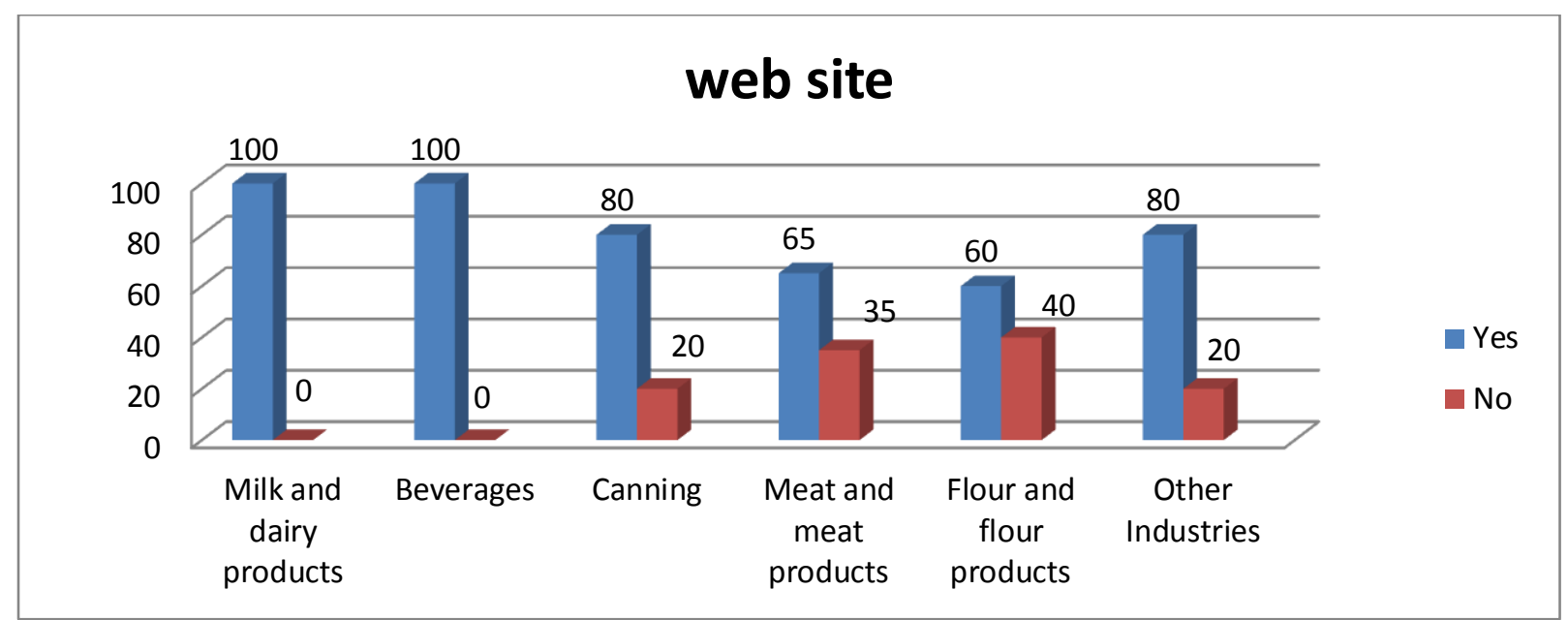

Figure 1: Web Analytics

\subsection{The results of the second question}

None of the companies studied exist on the web website of e-commerce and Internet sales do not use. . In fact, if we are very optimistic about the role of websites in the sale of food industry companies studied look at some of them may be called E-Business companies, services and customers to buy goods or services your dealer or sales representative should refer to the physical stores. But in addition to the introduction of goods and services E-Commerce site, the seller can buy online is also provided for the customer and the customer via the Internet by visiting the website of the seller of goods or services that you can select and order where's the money to pay the delivery of goods or services purchased on the track.

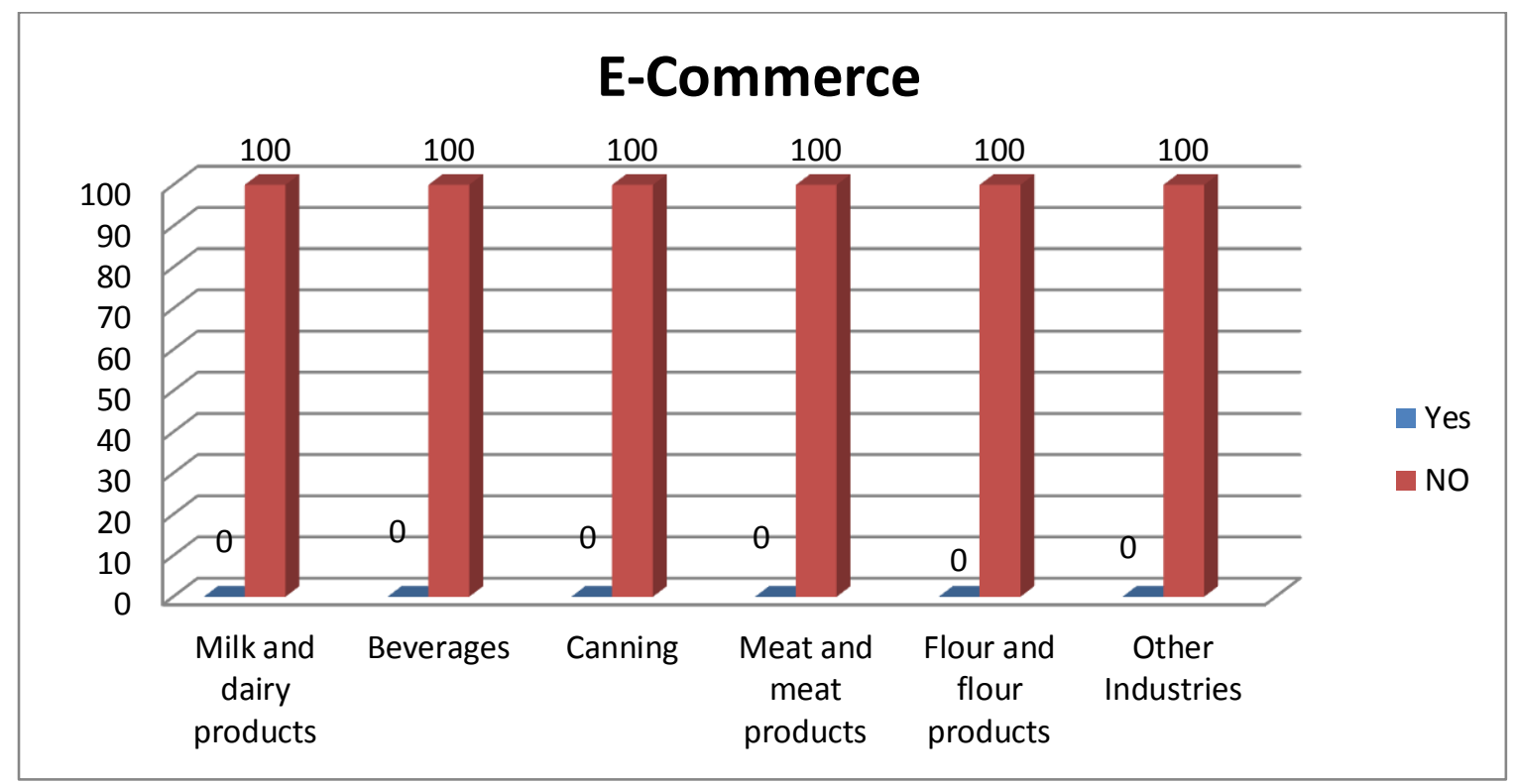

Figure 2: Analysis of E-Commerce

\subsection{The results of the third question}

None of the companies in the study of a Web site from the Internet and social networking sites on the web do not use and the advantages and benefits of using social networking sites and Internet advertising, including: Design high speed, low cost than television and radio advertising, Eliminating or minimizing the costs of the printed catalogs, need less staff in ads, Advertising cover the broader and growing bilateral or interaction Internet advertising, The ability to use text, audio, image and video in Internet advertising, the ability to deliver high volumes of data customers do not have to cost much less. 


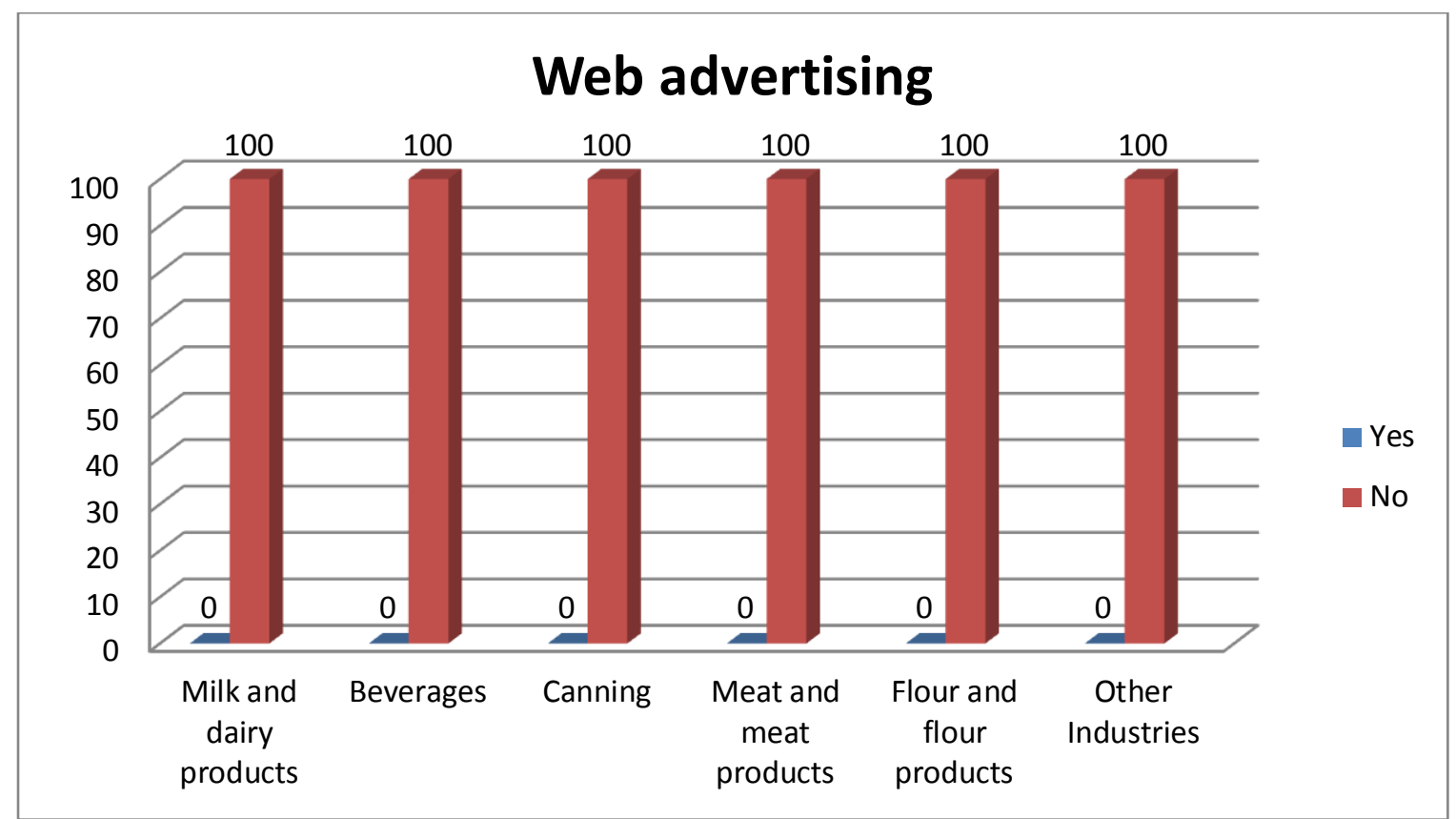

Figure 3: Analysis of Internet advertising and Social Network

\subsection{The results of the fourth question}

Milk and dairy products: all companies studied in this industry, so do customer relationship management. Beverages: $80 \%$ of companies in this industry, so do customer relationship management. Canning: $70 \%$ of companies in this industry, so do customer relationship management. Flour and flour products: $70 \%$ of companies in this industry, so do customer relationship management. Meat and meat products: all surveyed companies in this industry are lacking in customer relationship management. Other industries: $40 \%$ of companies in this industry, so do customer relationship management. Customer relationship management unit have a traditional CRM, and only in response to customer complaints or form periodic survey of customers, and none of the units studied modern CRM to the Internet or using software not do.

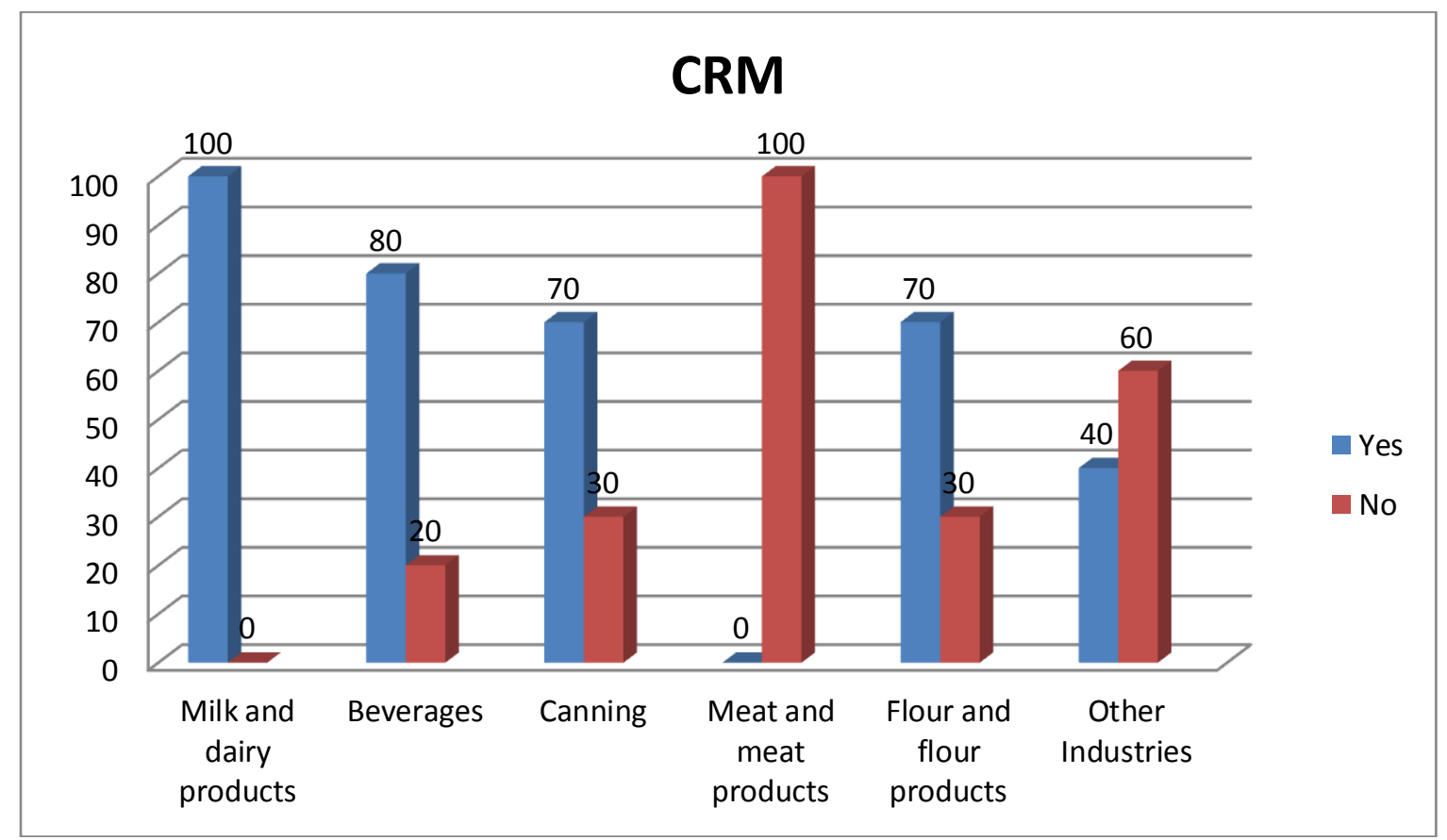

Figure 4: Analysis of customer relationship management 


\section{Conclusions}

The study found that unit sites, Some of these sites are complete conditions for E-Business site First to introduce our company and products and address of the dealership and distribution have announced products, But most companies have used the site as an introduction and some years are not an eternity. Unfortunately, none of the companies surveyed do not use the Internet advertising and social networking. The role and effectiveness of CRM is a customer relationship management firms that you are not well understood. Because none of CRM companies do not scientifically and a specific group or person in manufacturing unit is responsible for customer relationship management, for example, only the voice of the customer's phone or respond to their complaints, it is also responsible for responding to different units depending on the tastes of its senior managers. In some units, responding to direct complaints are completely responsible for quality control manager in charge of public relations, and some sales manager, So can not comment on the actual position of CRM in the company. However, few of the companies that form the evaluation of product quality and customer relationship are held periodically. Many modern methods of viral marketing and guerrilla marketing including the use of new technologies and social software is that unfortunately our companies the opportunity of modern, new and cheap to do. Perhaps the reason why managers of our companies is the subject of a separate investigation but the lack of awareness of the potential of new methods or lack of trust, one of the main reasons for it.

\section{Refrences}

Mashhadi, Mostafa. 2014. The Role of IT management in production, sales and quality control in food industries Khorasan Razavi, M.S.thesis, Quchan Branch, Islamic Azad University, Quchan, Iran. 